\title{
Comparison of residual salivary fluoride retention using amine fluoride toothpastes in caries-free and caries-prone children
}

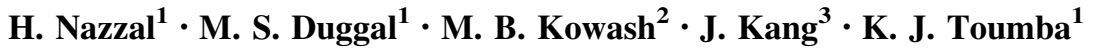

Received: 15 July 2015/ Accepted: 11 December 2015/Published online: 21 April 2016

(c) The Author(s) 2016. This article is published with open access at Springerlink.com

\begin{abstract}
Aim This was to compare the salivary fluoride levels following tooth brushing with amine fluoride toothpastes containing three different concentrations of $\mathrm{F}(250 \mathrm{ppm} \mathrm{F}$, $500 \mathrm{ppm} F$ and $1250 \mathrm{ppm} \mathrm{F}$ ) and to evaluate the effect of rinsing with water on the oral fluoride levels up to $90 \mathrm{~min}$. Methods A double blind randomised six-arm crossover study was conducted with 32 child participants. Patients were divided into two groups depending on their caries experience with caries-free group $(n=17$, mean age $=72.9$ months $)$ and caries-prone group $(n=15$, mean age $=69.6$ months, mean $\mathrm{dmfs}=12.3$ ). Each participant brushed their teeth with a smear of dentifrice containing ( $250 \mathrm{ppm}, 500 \mathrm{ppm}$ and $1250 \mathrm{ppm} \mathrm{F}$ toothpastes) for $60 \mathrm{~s}$. After spitting out the dentifrice/saliva slurry, participants either rinsed with water or did not rinse at all. Samples of whole mixed unstimulated saliva were collected at 0 (baseline), 1, 15, 30, 45, 60 and 90 mins post-brushing/ rinsing.

Results After completing the study on residual fluoride concentration it was found that caries was not a significant variable $(p=0.567)$ while every other variable was (all $p$ values $<0.001)$. Time, toothpaste $\mathrm{F}$ concentration and rinse had significant effects $(p<0.001)$. In general, higher residual salivary $F$ concentrations were found with
\end{abstract}

\section{H. Nazzal}

denha@leeds.ac.uk; haninazzal@hotmail.com

1 Department of Paediatric Dentistry, Leeds Dental Institute, Leeds, UK

2 Hamdan Bin Mohamed College of Dental Medicine, Dubai, United Arab Emirates

3 Department of Oral Biology, Leeds Dental Institute, Leeds, UK increased $\mathrm{F}$ concentration in toothpastes and when no rinsing was performed after brushing.

Conclusion The results of this study support the current recommendation of using toothpastes with $>1000 \mathrm{ppm} \mathrm{F}$ concentration in children with an increased caries risk in addition to spitting excess toothpaste with no rinsing following brushing.

Keywords Amine Fluoride - Children - Clearance . Fluoride - Saliva · Toothpaste

\section{Introduction}

Despite the dental profession's continuous efforts in preventing dental caries, $31 \%$ of 5 year olds and $46 \%$ of 8 year olds were found to have obvious dental decay affecting their primary teeth according to the UK (2013) child dental health survey (Pitts et al. 2015). There are several prevention systems available, however, yet the use of fluoride $(\mathrm{F})$ remains the most effective caries prevention tool, with overwhelming evidence of anti-cariogenic effect. Researchers have shown higher salivary fluoride levels in caries-free subjects in comparison to high caries subjects in both fluoridated and non-fluoridated areas $(0.04 \mathrm{mg} / \mathrm{L}$ or greater in comparison to $0.02 \mathrm{mg} / \mathrm{L}$ or less) (Leverett et al. 1987; Shields et al. 1987; Toumba and Curzon 2001).

Several fluoride delivery systems are currently available; however, the use of fluoridated toothpastes is still the most widely used method. The use of fluoridated toothpastes was shown to elevate salivary fluoride levels and reduce dental decay (Walsh et al. 2010). A recent Cochrane review concluded that higher relative caries preventive effects were associated with increased toothpaste fluoride concentrations (Walsh et al. 2010). This effect, however, 
was significant for toothpastes containing $1000 \mathrm{ppm}$ fluoride and above, with lack of evidence supporting toothpastes with lower fluoride concentrations. This led to the recommendation of using toothpastes with higher fluoride concentrations such as $1000 \mathrm{ppm}$ fluoride in under 3 year olds and $>1350 \mathrm{ppm}$ fluoride for older children and those with increased caries risk (Department of Health and British Association for the Study of Community Dentistry 2014)

Regardless of the fluoride delivery method used, maintaining a low level of salivary fluoride $(0.06 \mathrm{mg} / \mathrm{L})$ at the plaque/saliva/enamel interphase has been shown to reduce dental caries (ten Cate 1997; Featherstone 1999). Therefore, it is important to study salivary fluoride clearance following tooth brushing and identify any associated factors influencing salivary fluoride retention.

In adults, fluoride clearance has been investigated by several researchers showing a link between salivary fluoride levels and fluoride concentration of the toothpaste (Duckworth and Morgan 1991; Duckworth and Stewart 1994). Such studies, however, have rarely involved children. Paul et al. (1993) reported a similar trend when using low fluoride toothpaste in 50 children between 7 and 9 years of age.

Salivary fluoride clearance following tooth brushing can also be affected by other factors such as mouth rinsing with water following brushing. Research conducted on adults has shown that rinsing habits might affect oral retention of fluoride following brushing (Duckworth and Morgan 1991).

Issa and Toumba in (2004) compared different types of toothpastes (amine fluoride, sodium monofluorophosphate and sodium fluoride) with different concentrations (250-1450 ppm F) followed by either rinsing with water or not rinsing, in a randomised controlled trial. The highest salivary $\mathrm{F}$ retention was observed with amine $\mathrm{F}$ toothpastes containing $1400 \mathrm{ppm} \mathrm{F}$ throughout the study (up to $120 \mathrm{~min}$ ).

The following study was designed to compare the salivary fluoride levels following tooth brushing in young children with amine fluoride toothpastes containing three different concentrations of $F(250 \mathrm{ppm} \mathrm{F}, 500 \mathrm{ppm} F$ and $1250 \mathrm{ppm} \mathrm{F}$ ) and evaluate the effect of rinsing with water on the oral fluoride levels up to $90 \mathrm{~min}$. An additional aim was to evaluate whether there were differences in the oral salivary $\mathrm{F}$ clearance between caries-free and caries-prone children using amine $\mathrm{F}$ toothpastes.

The null hypothesis was that residual salivary F concentrations were not affected by toothpaste $\mathrm{F}$ concentration, water rinsing and the child's dental caries experience.

\section{Materials and methods}

Ethical approval was obtained from the local research ethics committee of the Leeds Teaching Hospitals NHS Trust and consent/assent was obtained from the person with parental responsibility and each child prior to recruitment. Thirty-two children comprising 17 in the caries-free group (mean age $=72.9$ months, and $\mathrm{dmfs}=0$ ) and 15 in the caries-prone group (mean age $=69.6$ months, and mean $+\mathrm{SD}$ dmfs $=12.3 \pm 6.1)$ participated in this double blind randomised six-arm crossover study.

Participants used F-free toothpaste for 1 day prior to each leg of the study. Every participant in each group (caries-free and caries-prone) brushed their teeth with a smear $(0.2 \mathrm{~g})$ of dentifrice $(250 \mathrm{ppm}, 500 \mathrm{ppm}$ and $1250 \mathrm{ppm} F$ toothpastes) for $60 \mathrm{~s}$. A computer generated randomisation table for the study arm order for each child was generated and kept independently of the researchers by another member of staff. Upon recruitment of patients, the independent staff member was contacted to inform the senior author and researcher with the study arm order. This was a double "blinded" study (identical coded tubes), therefore, neither patients nor clinicians were able to identify which fluoride concentration was used at each arm of the study. After spitting out the dentifrice/saliva slurry, participants either:

1. Rinsed with $10 \mathrm{~mL}$ of Leeds tap water $(0.1 \mathrm{ppm} \mathrm{F})$ for $10 \mathrm{~s}$ (rinsing group).

2. Did not rinse at all (non-rinsing group).

This was supervised by one of the team members who was not involved with the collection and measurements therefore the assessors were "blind" to the rinsing effect. Samples of whole mixed unstimulated saliva were collected at 0 (baseline), 1, 15, 30, 45, 60 and 90 min postbrushing/rinsing. Salivary F levels were analysed immediately using an Orion F ion-specific electrode.

\section{Statistical analysis}

The outcome variable (residual salivary fluoride concentration) was fitted with a linear mixed effect model with predictors as rinsing, caries experience, and concentration of toothpaste. The predictor effects were considered to be statistically significant at the $5 \%$ level. The model included a random intercept to account for the repeated observations (over time at $0,1,15,30,45,60$, and $90 \mathrm{~min}$ ) for each individual. All models were fitted using maximum likelihood estimation and backward elimination was used for model selection to obtain the parsimonious model. Statistical analysis was performed using IBM SPSS 
Statistics 21 software. A statistician, one of the authors of this manuscript $(\mathrm{JK})$, performed the statistical analyses.

\section{Results}

After obtaining the full model, it was found that dental caries was not a significant variable $(p=0.567)$ while every other variable was (all $p$ values $<0.001$ ). Therefore, dental caries was excluded in the new model. Time, toothpaste $\mathrm{F}$ concentration, and water rinsing had significant effects $(p<0.001)$. Interaction effects between any two of these variables were also significant. The three-way interaction between time, toothpaste $\mathrm{F}$ concentration and rinse was also significant.
Figures 1 and 2 show a similar pattern of salivary $F$ clearance with time regardless of toothpaste $\mathrm{F}$ concentration. In general higher residual salivary $F$ concentrations were found with higher $\mathrm{F}$ concentration in the toothpaste and when no rinsing was performed after brushing. Residual salivary $\mathrm{F}$ concentrations remained over the $0.06 \mathrm{ppm}$ salivary $\mathrm{F}$ threshold for caries prevention up to 90 min with 1250 ppm $\mathrm{F}$ toothpaste regardless of rinsing. The same pattern was observed for toothpastes containing 500 ppm F with no rinsing. The 250 ppm F containing toothpaste with rinsing dropped under the threshold after only $30 \mathrm{~min}$.

Figures 1 and 3 show that for any given toothpaste, the residual salivary fluoride levels were lower after rinsing with water.
Fig. 1 Line graph showing mean residual salivary fluoride concentrations after brushing with three amine fluoride toothpastes (250, 500 and $1250 \mathrm{ppm} F$ ) with rinsing and no rinsing over time

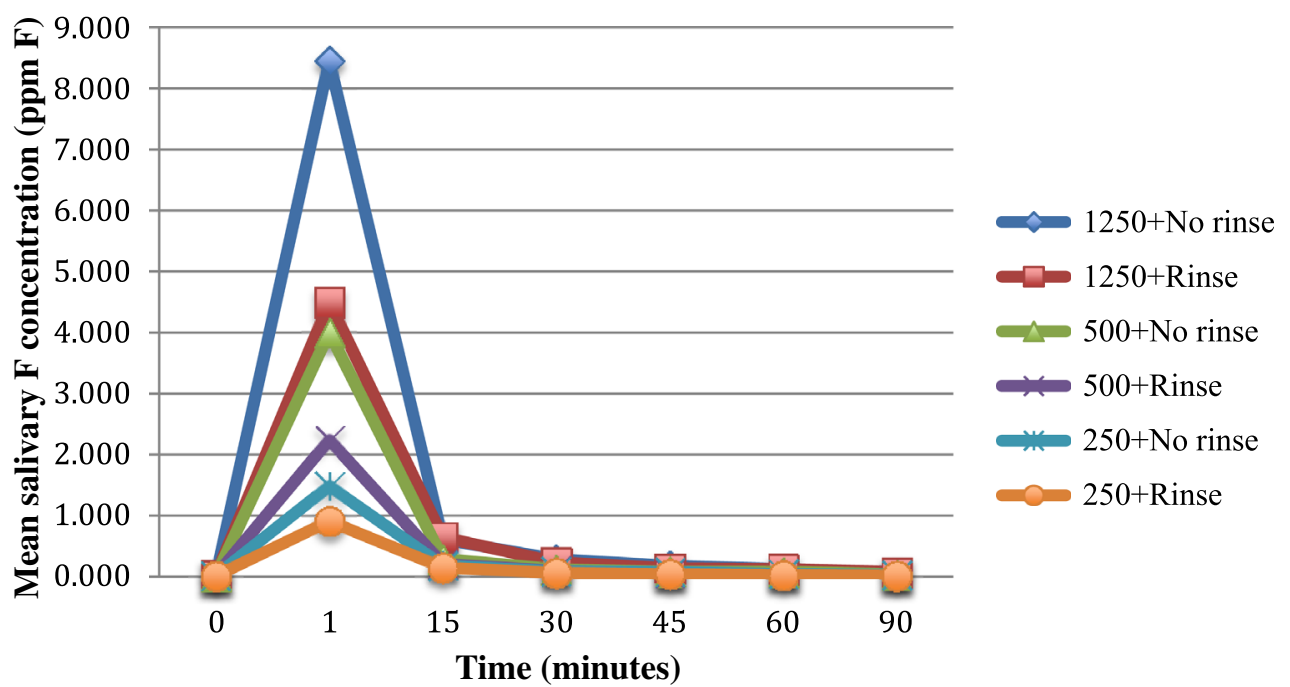

Fig. 2 Line graph showing mean residual salivary fluoride concentrations after brushing with three amine fluoride toothpastes $(250,500$ and $1250 \mathrm{ppm} F$ ) with rinsing and no rinsing over time in relation to the minimum anti-cariogenic salivary fluoride concentration of $0.06 \mathrm{ppm} \mathrm{F}$

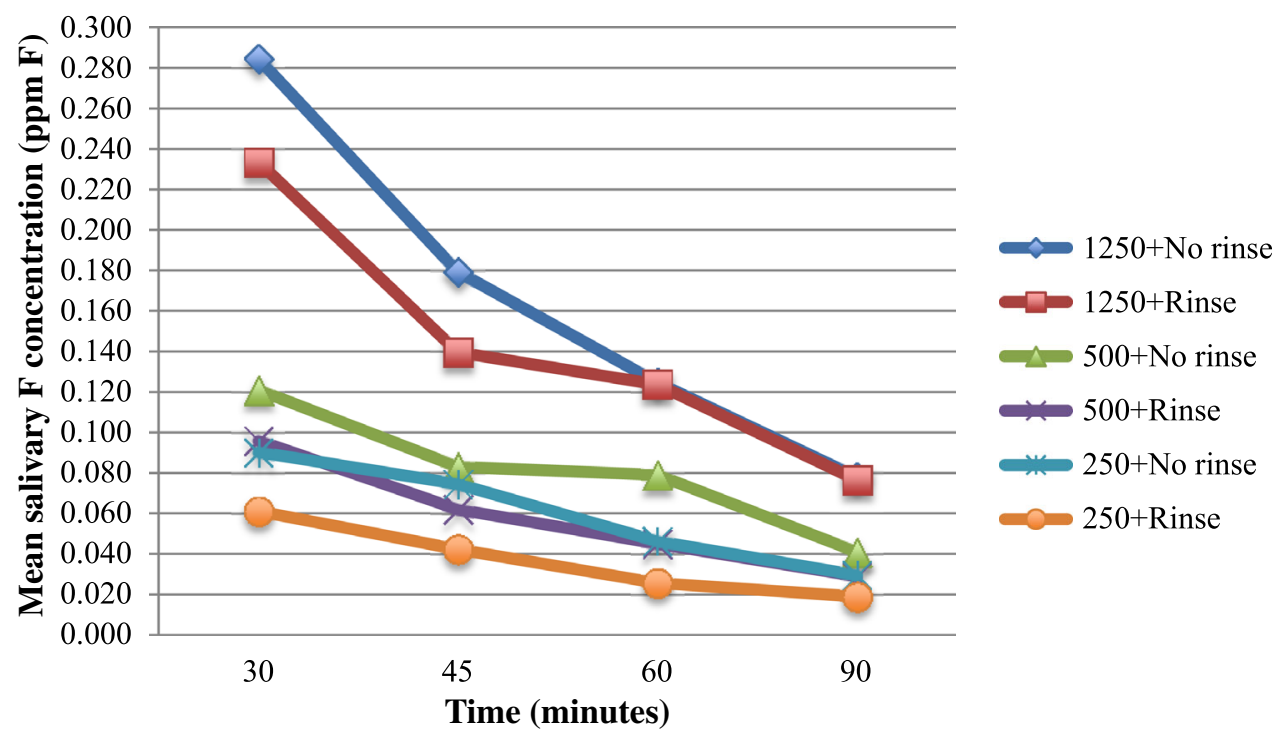


Fig. 3 Graph showing estimated marginal means of salivary fluoride concentrations between rinsing and no rinsing(excluding toothpaste fluoride concentration and caries as variables) at $0-90 \mathrm{mins}$

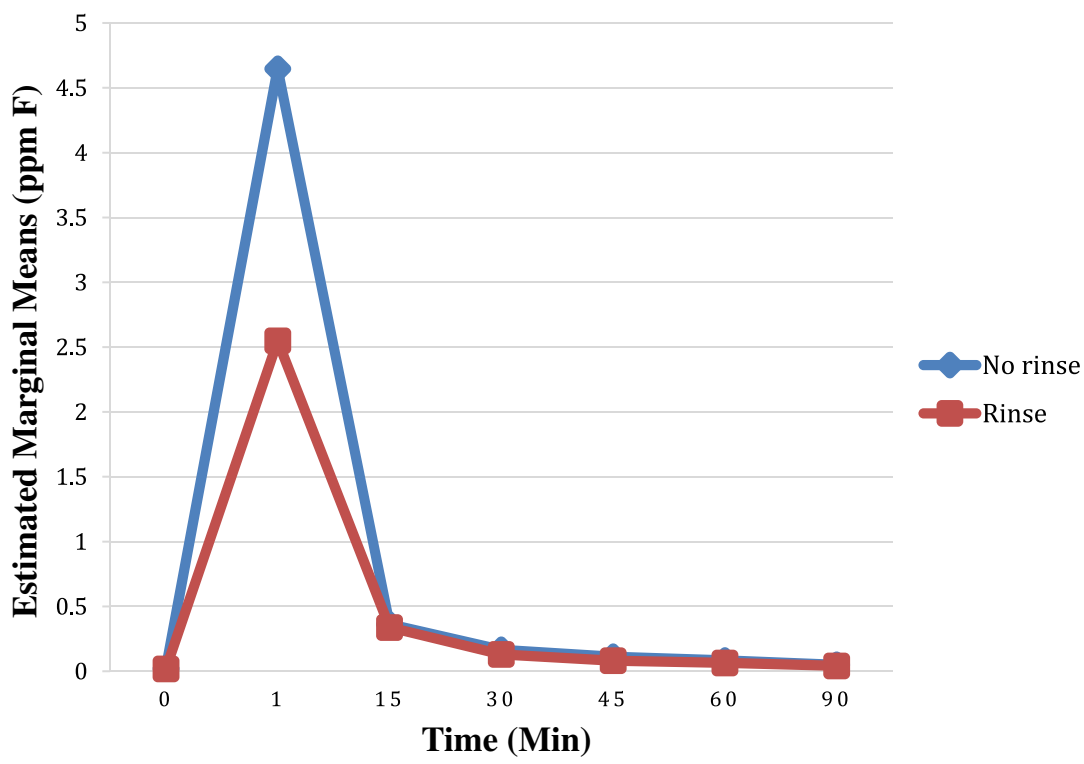

The effect of toothpaste $\mathrm{F}$ concentration showed the lowest $p$ value $(<0.001)$ and therefore should be considered the factor with the mostsignificant effect in the model. There are significant differences when comparing toothpastes with different $\mathrm{F}$ concentrations against each other (1250-250,1250-500, 250-500 ppm F, all $p$ values $<0.001)$. A higher residual salivary fluoride concentration was measured when using toothpaste with higher $F$ concentration.

\section{Discussion}

\section{Toothpaste $\mathrm{F}$ concentration}

The use of fluoridated toothpastes has been associated with reduction in dental caries (Walsh et al. 2010) with higher caries prevention associated with higher $\mathrm{F}$ concentration in toothpastes. The use of high $\mathrm{F}$ containing toothpastes, however, is associated with a higher risk of fluorosis (Atia and May 2013), therefore, assessing the anti-cariogenic effect and salivary $\mathrm{F}$ retention of toothpastes with lower $\mathrm{F}$ concentrations is indicated.

The use of $1400 \mathrm{ppm}$ amine $\mathrm{F}$ containing toothpastes was shown to increase salivary $\mathrm{F}$ levels up to $120 \mathrm{~min}$ in children (Issa and Toumba 2004). Similar results were found in adults following use of amine fluoride toothpaste (1250 ppm F for $90 \mathrm{~min}$ ) (Attin and Hellwig 1996). Therefore, this study compared three different amine $\mathrm{F}$ concentrations with lower F concentrations (250, 500 and 1250 ppm F). The pattern of salivary F concentrations over time was similar for all toothpastes used which is consistent with the work by Issa and Toumba (2004). Residual salivary $\mathrm{F}$ concentrations were highest after $1 \mathrm{~min}$ regardless of toothpaste used followed by steep reduction up to $15 \mathrm{~min}$. This was then followed by gradual reduction up to 90 min regardless of toothpaste F concentration.

Toothpaste F concentration was the variable showing the most significant effect in the model, used to analyse the results of this study. Furthermore, salivary F concentrations remained over the 0.06 ppm salivary $\mathrm{F}$ threshold for caries prevention up to 90 min with $1250 \mathrm{ppm} F$ toothpaste regardless of rinsing experience. Therefore, based on the results of this study using 1250 ppm F containing toothpaste is recommended.

Based on the pattern of $F$ clearance, seen in all types of toothpaste used in this study, salivary $\mathrm{F}$ concentrations gradually decreased to a level under the recommended $0.06 \mathrm{ppm} \mathrm{F}$. Therefore regular brushing is recommended in order to maintain salivary F concentrations over the recommended levels.

Although no high quality evidence is available on the effect of brushing before or after meals, in vitro evidence showed less mineral loss with brushing before meals (Toumba 2012). The maximum protection of $F$ toothpastes in this study seems to be within the first $1-15 \mathrm{~min}$ and therefore for $\mathrm{F}$ to exhibit the maximum anti-cariogenic effect, tooth brushing just before a cariogenic challenge is recommended. In addition, Sjögren and Birkhed (1994) showed 12-15 times reduction in residual $F$ levels immediately following eating and when brushing was performed before eating which could indicate the utilisation of $\mathrm{F}$ in cariogenic areas.

\section{Rinsing after tooth brushing}

This study showed that, in general, rinsing the mouth with water after brushing was associated with lower residual 
salivary $\mathrm{F}$ concentrations which was consistent with the studies conducted on adults (Attin and Hellwig 1996). The use of $500 \mathrm{ppm} \mathrm{F}$ containing toothpaste followed by no rinsing was associated with residual salivary $\mathrm{F}$ levels higher than $0.06 \mathrm{ppm} F$ up to $90 \mathrm{~min}$, which was similar to the 1250 ppm F toothpaste. The use of 1250 ppm F containing toothpaste, however, might provide longer protection than $90 \mathrm{~min}$ (Fig. 2). Figure 2 shows no effect of rinsing on mean salivary $\mathrm{F}$ concentrations after $60 \mathrm{~min}$, however, in the statistical model used herein showed rinsing to have a significant effect regardless of $F$ toothpaste concentration.

\section{Conclusion}

The null hypothesis is therefore rejected with regards to the effect of higher $\mathrm{F}$ containing toothpaste and rinsing following tooth brushing on residual salivary $\mathrm{F}$ concentrations. The null hypothesis is accepted with regards to the effect of caries experience on residual salivary $F$ concentrations.

The results of this study, therefore, support the current recommendation of spitting excess toothpaste with no rinsing following brushing (Department of Health and British Association for the study of Community Dentistry 2014). In addition, this study supports the recommendation to use toothpastes with $>1000 \mathrm{ppm} \mathrm{F}$ concentration in children with an increased caries risk.

Acknowledgments This study was supported by GABA International Limited, Switzerland. However, the authors would like to declare no conflict of interests.

Open Access This article is distributed under the terms of the Creative Commons Attribution 4.0 International License (http://crea tivecommons.org/licenses/by/4.0/), which permits unrestricted use, distribution, and reproduction in any medium, provided you give appropriate credit to the original author(s) and the source, provide a link to the Creative Commons license, and indicate if changes were made.

\section{References}

Atia GS, May J. Dental fluorosis in the paediatric patient. Dent Update. 2013;40:836-9.

Attin T, Hellwig E. Salivary fluoride content after toothbrushing with a sodium fluoride and an amine fluoride dentifrice followed by different mouthrinsing procedures. J Clin Dent. 1996;7:6-8.

Department of Health and British Association for the study of Community Dentistry. Delivering Better Oral Health. An evidence-based toolkit for prevention. London; 2014.

Duckworth R, Morgan S. Oral fluoride retention after use of fluoride dentrifices. Caries Res. 1991;25:123-9.

Duckworth R, Stewart D. Effect of mouthwashes of variable $\mathrm{NaF}$ concentration but constant $\mathrm{NaF}$ content on oral fluoride retention. Caries Res. 1994;8:43-7.

Featherstone J. Prevention and reversal of dental caries: role of low level fluoride. Community Dent Oral Epidemiol. 1999;27:31-40.

Issa AI, Toumba KJ. Oral fluoride retention in saliva following toothbrushing with child and adult dentifrices with and without water rinsing. Caries Res. 2004;38:15-9.

Leverett D, Adair S, Shields C, et al. Relationship between between salivary and plaque fluoride levels and dental caries experience in fluoridated and non-fluoridated communities. Caries Res. 1987;21:179 (Abst 57).

Paul S, Tandon S, Murthy K. Effect of fluoride dentifrices on salivary fluoride levels in children. Indian J Dent Res. 1993;4:95-101.

Pitts N, Chadwick B, Anderson T. Child Dental Health Survey 2013, England, Wales and Northern Ireland [NS]. 2015. http://www. hscic.gov.uk/catalogue/PUB17137, Accessed May 2015.

Shields C, Leverett D, Adair S, et al. Salivary fluoride levels in fluoridated and non-fluoridated communities. J Dent Res. 1987;141:Abst 277.

Sjögren K, Birkhed D. Effect of various post-brushing activities on salivary fluoride concentration after toothbrushing with a sodium fluoride dentrifice. Caries Res. 1994;28:127-31.

ten Cate J. Review on fluoride, with special emphasis on calcium fluoride mechanisms in caries prevention. Eur J Oral Sci. 1997; 105:461-5.

Toumba J. Tooth brushing before or after breakfast? Eur Arch Paediatr Dent. 2012;13:107.

Toumba K, Curzon M. Fluoride concentrations in saliva related to dental caries in primary teeth. Eur J Paediatr Dent. 2001;2:15-9.

Walsh T, Worthington HV, Glenny A-M, et al. Fluoride toothpastes of different concentrations for preventing dental caries in children and adolescents. Cochrane Database of Sys Rev [Online]. 2010. http:// onlinelibrary.wiley.com/doi/10.1002/14651858.CD007868.pub2/ abstract. Accessed 9 July 2015. 